\title{
Glucagon increases circulating fibroblast growth factor 21 independently of endogenous insulin levels: a novel mechanism of glucagon-stimulated lipolysis?
}

\author{
A. M. Arafat • P. Kaczmarek • M. Skrzypski • \\ E. Pruszyńska-Oszmalek • P. Kołodziejski • \\ D. Szczepankiewicz • M. Sassek • T. Wojciechowicz • \\ B. Wiedenmann • A. F. H. Pfeiffer • K. W. Nowak • \\ M. Z. Strowski
}

Received: 1 August 2012 / Accepted: 23 November 2012 /Published online: 22 December 2012

(C) Springer-Verlag Berlin Heidelberg 2012

\begin{abstract}
Aims/hypothesis Glucagon reduces body weight by modifying food intake, glucose/lipid metabolism and energy expenditure. All these physiological processes are also controlled by fibroblast growth factor 21 (FGF-21), a circulating hepatokine that improves the metabolic profile in obesity and type 2 diabetes. Animal experiments have suggested a possible interaction between glucagon and FGF-21 however, the metabolic consequences of this crosstalk are not understood.

Methods The effects of exogenous glucagon on plasma FGF21 levels and lipolysis were evaluated in healthy volunteers
\end{abstract}

Electronic supplementary material The online version of this article (doi:10.1007/s00125-012-2803-y) contains peer-reviewed but unedited supplementary material, which is available to authorised users.

A. M. Arafat • A. F. H. Pfeiffer

Department of Endocrinology, Diabetes and Nutrition,

Charité-University Medicine Berlin, Berlin, Germany

\section{A. M. Arafat • A. F. H. Pfeiffer}

Department of Clinical Nutrition, German Institute of Human

Nutrition Potsdam-Rehbruecke, Nuthetal, Germany

P. Kaczmarek • M. Skrzypski • E. Pruszyńska-Oszmalek •

P. Kołodziejski · D. Szczepankiewicz • M. Sassek •

T. Wojciechowicz $\cdot$ K. W. Nowak

Department of Animal Physiology and Biochemistry,

Poznań University of Life Sciences, Poznań, Poland

M. Skrzypski • M. Sassek • B. Wiedenmann • M. Z. Strowski ( $₫)$

Department of Hepatology and Gastroenterology

\& the Interdisciplinary Centre of Metabolism: Endocrinology,

Diabetes and Metabolism, Charité-University Medicine Berlin,

Campus Virchow-Klinikum, Augustenburger Platz 1,

13353 Berlin, Germany

e-mail: mathias.strowski@charite.de and humans with type 1 diabetes, as well as in rodents with streptozotocin (STZ)-induced insulinopenic diabetes. In vitro, the role of glucagon on FGF-21 secretion and lipolysis was studied using isolated primary rat hepatocytes and adipocytes. Fgf-21 expression in differentiated rat pre-adipocytes was suppressed by small interfering RNA and released FGF-21 was immunoneutralised by polyclonal antibodies.

Results Glucagon induced lipolysis in healthy human volunteers, patients with type 1 diabetes, mice and rats with STZ-induced insulinopenic diabetes, and in adipocytes isolated from diabetic and non-diabetic animals. In addition, glucagon increased circulating FGF-21 in healthy humans and rodents, as well as in patients with type 1 diabetes, and insulinopenic rodents. Glucagon stimulated FGF-21 secretion from isolated primary hepatocytes and adipocytes derived from animals with insulinopenic diabetes. Furthermore, FGF21 stimulated lipolysis in primary adipocytes isolated from non-diabetic and diabetic rats. Reduction of $F g f-21$ expression (by approximately 66\%) or immunoneutralisation of released FGF-21 markedly attenuated glucagon-stimulated lipolysis in adipocytes.

Conclusions/interpretation These results indicate that glucagon increases circulating FGF-21 independently of endogenous insulin levels. FGF-21 participates in glucagon-induced stimulation of lipolysis.

Keywords Adipocytes - Animal study · Endocrine pancreas · Glucose homeostasis · Hepatocytes · Human study .

Secretion - Type 1 diabetes
Abbreviations
EMEM Eagle's minimum essential medium
FGF-21 Fibroblast growth factor 21 


$\begin{array}{ll}\text { GH } & \text { Growth hormone } \\ \text { LP } & \text { Lean healthy participants } \\ \text { nTZD } & \text { Non-thiazolidinedione PPAR } \gamma \text { agonist } \\ \text { PPAR } \gamma & \text { Peroxisome proliferator-activated receptor } \gamma \\ \text { siRNA } & \text { Small interfering RNA } \\ \text { STZ } & \text { Streptozotocin }\end{array}$

\section{Introduction}

Fibroblast growth factor 21 (FGF-21) is a member of a family of atypical fibroblast growth factors predominantly produced in the liver $[1,2]$. Rodent studies have shown that during fasting FGF-21 stimulates hepatic fatty acid oxidation, ketogenesis, lipolysis and gluconeogenesis to supply metabolically active tissues with substrates [3, 4]. However, another animal study showed that in the fasting state FGF21 inhibits lipolysis, whereas in the fed state FGF-21 stimulates it [5]. In vitro, FGF-21 stimulates lipolysis in murine 3T3-L1 adipocytes [3], whereas opposite effects have been observed in isolated human adipocytes [6].

Serum FGF-21 concentrations are elevated in patients with obesity and metabolic syndrome [7], while increased levels of FGF-21 in the liver and adipose tissues were reported in obese $d b / d b$ mice [7]. FGF-21 alleviates hyperglycaemia, improves lipid profile and reduces body weight in animal models with type 2 diabetes and obesity $[1,8]$.

Increased glucagon and low insulin levels contribute to the maintenance of normoglycaemia during the fasting state. In adipocytes glucagon stimulates lipolysis, whereas in hepatocytes glucagon inhibits glycolysis, triacylglycerol synthesis, and stimulates gluconeogenesis, glycogenolysis, ketogenesis and beta oxidation of NEFA [9-11].

As with glucagon, plasma concentrations of FGF-21 and hepatic $F g f-21$ mRNA expression increase during fasting and starvation, whereas in the fed state $F g f-21$ expression and plasma protein levels are low [2, 6-8].

Discordant data exist regarding the impact of glucagon on FGF-21 production and plasma levels. In rodents glucagon seems to stimulate $F g f-21$ expression in vitro and in vivo [12-15], and these effects are somewhat augmented by NEFA [15]. However, another study reported that glucagon fails to stimulate hepatic Fgf-21 mRNA expression in rodents [16].

Discrepant observations were also reported regarding the role of insulin in glucagon-stimulated FGF-21 production [15]. In non-diabetic humans, an approximately sevenfold increase in circulating insulin was associated with a minimal elevation of FGF-21 [17]. In contrast, circulating FGF-21 increased after insulin was removed from patients with type 1 diabetes [18]. In vitro, insulin inhibited glucagon-stimulated hepatic Fgf-21 expression in rodents [12].

In light of these inconsistencies, the aim of the current study was to investigate whether endogenous insulin influences the glucagon-dependent regulation of FGF-21 production, secretion and FGF-21 plasma levels. This question was addressed in a prospective study involving healthy individuals, humans with type 1 diabetes, as well as animals with streptozotocin (STZ)induced insulinopenic diabetes. Complementary experiments were performed on isolated hepatocytes and adipocytes. In addition, the study investigates the impact of glucagon on lipolysis in vivo and in vitro and proposes FGF-21 as novel mediator of the lipolytic activity of glucagon.

\section{Methods}

Randomised controlled human study

Participants Prospective investigations were performed in 13 consecutively recruited lean healthy participants (LP) and in 13 patients with type 1 diabetes (Table 1). LP underwent standard endocrine tests [19] to exclude any hypothalamo-pituitary abnormalities. Inclusion and exclusion criteria are listed in electronic supplementary material (ESM) Table 1. The study protocol was approved by the Ethical Committee of the Charite University of Berlin and performed according to the requirements of the Declaration of Helsinki. Written informed consent was obtained from all participants. The trial was registered at ClinicalTrials.gov (registration number NCT00929812).

Study procedures In all participants, a full medical history was obtained, followed by physical examination. In a double-blind crossover design, LP and patients received either glucagon (1 mg GlucaGen; Novo Nordisk Pharma,

Table 1 Baseline characteristics of type 1 diabetic patients and LP

\begin{tabular}{lll}
\hline Characteristic & Diabetic patients & LP \\
\hline Age (years) & $32.3 \pm 2.1^{* * *}$ & $25.1 \pm 0.6$ \\
Sex (males/females) & $6 / 7$ & $6 / 7$ \\
Anthropometry & & \\
$\quad$ Body mass index (kg/m²) & $24.8 \pm 0.95^{* *}$ & $21.7 \pm 0.6$ \\
Waist circumference (cm) & $91.2 \pm 3.6^{* *}$ & $79.6 \pm 1.8$ \\
Waist/hip ratio & $0.9 \pm 0.02^{* *}$ & $0.86 \pm 0.01$ \\
Body composition & & \\
Truncal fat mass (\%) & $24.2 \pm 2$ & $20.4 \pm 1.6$ \\
Truncal lean mass (\%) & $44.7 \pm 1.8$ & $44.2 \pm 1.4$ \\
Biochemical variables & & \\
Fasting glucose (mmol/1) & $5.3 \pm 0.4$ & $4.5 \pm 0.2$ \\
Fasting insulin (pmol/1) & $7.1 \pm 0.1^{* *}$ & $32.9 \pm 4.1$ \\
Fasting glucagon (ng/l) & $41.7 \pm 3.4$ & $38.4 \pm 3.95$ \\
FGF-21 (ng/ml) & $0.33 \pm 0.05^{* *}$ & $0.14 \pm 0.01$ \\
\hline
\end{tabular}

Values are presented as mean \pm SEM

${ }^{* * *} p<0.01$ compared with LP 
Bagsværd, Denmark) or placebo intramuscularly, as described previously [20]. Type 1 diabetic patients were asked to omit their insulin only on the morning of the test, but received their long-acting insulin analogue on the evening before the test. Participants remained supine until the end of the test. Blood samples were taken at 30,60,120, 180 and 240 min after the glucagon injection; serum and EDTA plasma samples were stored at $-80^{\circ} \mathrm{C}$.

Animal studies

Animals The experiments were approved by the Local Ethics Commission for Investigation on Animals, Poznań University of Life Sciences. The recommendations set out in 'Principles of laboratory animal care' (NIH publication no. 85-23, revised 1985; http:/grants1.nih.gov/grants/olaw/ references/phspol.htm) were followed. Adult male Wistar

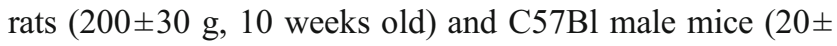
$4 \mathrm{~g}, 16$ weeks old) were from Lab Animal Breeding (Brwinow, Poland) and Academic Experimental Animal House (Research and Service Center, University of Gdansk, Poland). Animals were housed at a constant temperature, $12 / 12 \mathrm{~h} \mathrm{light/}$ dark cycle and fed a standard laboratory diet (Labofed-H, Kcynia, Poland), with free access to water. Animals were allowed to recover for 2 weeks.

Induction of insulinopenic diabetes Diabetes was induced in rats by STZ ( $65 \mathrm{mg} / \mathrm{kg}$ body weight i.p.). In mice, pancreatic beta cells were destroyed by STZ injected i.p. at day 0 (100 mg/kg body weight) and day $7(80 \mathrm{mg} / \mathrm{kg}$ body weight) [21-23]. Blood glucose and fasting insulin concentrations were assayed 4 days after STZ administration (rats) or 7 days after the second STZ injection (mice). Insulinopenic diabetes was confirmed by undetectable plasma insulin $(<17 \mathrm{pmol} / \mathrm{l})$ and blood glucose concentrations $\geq 16.6 \mathrm{mmol} / \mathrm{l}$ (Table 2).

In vivo animal studies After a 4 or $24 \mathrm{~h}$ fast, glucagon ( $0.05 \mathrm{mg} / \mathrm{kg}$ body weight $) \pm$ des-His1[Glu9] glucagon amide ( $2 \mathrm{mg} / \mathrm{kg}$ body weight) or vehicle was injected i.p. Blood $(15 \mu \mathrm{l})$ was collected from tail veins. Animals were decapitated $4 \mathrm{~h}$ after injection and blood and tissues were collected.

Materials Unless otherwise stated, all reagents were purchased from Sigma-Aldrich (Deisenhofen, Germany). Specifications and dilutions of antibodies are given in ESM Table 2. DMEM, Eagle's minimal essential medium (EMEM), Hanks' balanced salt solution and supplements were obtained from Gibco Invitrogen (Karlsruhe, Germany). The nonthiazolidinedione peroxisome proliferator-activated receptor $\gamma$ (PPAR $\gamma$ ) agonist (nTZD), indole-acetic acid (2-[2-(4-phenoxy2-propylphenoxy)ethyl] indole-5-acetic acid), was from MSD (Rahway, NJ, USA) [24]. Recombinant mouse FGF-21 was obtained from Biovision (Milpitas, CA, USA).
Table 2 Baseline metabolic profile of mice and rats with experimentally induced insulinopenic diabetes and corresponding non-diabetic healthy controls

\begin{tabular}{llllll}
\hline Variable & \multicolumn{2}{l}{ Mice } & & & \multicolumn{2}{l}{ Rats } \\
\cline { 2 - 3 } \cline { 6 - 6 } & Diabetic $^{\mathrm{a}}$ & Control & & Diabetic $^{\mathrm{a}}$ & Control \\
\hline Glucose $(\mathrm{mmol} / \mathrm{l})$ & $22 \pm 5.4$ & $6.0 \pm 1.5$ & $>33$ & $6.7 \pm 1.4$ \\
Insulin $(\mathrm{pmol} / \mathrm{l})$ & $\mathrm{ND}$ & $367 \pm 220$ & & ND & $554 \pm 290$ \\
FGF-21 $(\mathrm{pg} / \mathrm{ml})$ & $58 \pm 33^{* * *}$ & $213 \pm 34$ & & $23 \pm 1.3^{* * *}$ & $44 \pm 3.2$ \\
Glucagon $(\mathrm{pg} / \mathrm{ml})$ & $129 \pm 23^{*}$ & $61 \pm 13$ & & $267 \pm 53^{*}$ & $139 \pm 38$ \\
\hline
\end{tabular}

Results are expressed as means \pm SEM derived from at least five animals per group

${ }^{\mathrm{a}} \mathrm{STZ}$-induced insulinopenic diabetes

${ }^{*} p<0.05$ and ${ }^{* * *} p<0.001$ compared with control animals

$\mathrm{ND}$, not detectable

Hormone assays Blood glucose, serum insulin and plasma glucagon levels were assessed, as described [20]. NEFA were measured by a calorimetric assay (NEFA C; Wako, Neuss, Germany) performed with a Cobas Mira (Roche, Basel, Switzerland). The inter-assay CV was $4.7 \%$. FGF21 levels were determined using a human RIA (Phoenix Europe, Karlsruhe, Germany). The intra-assay CV was $4.1 \%$ and the inter-assay $\mathrm{CV}$ was $9.2 \%$.

Isolation of rat hepatocytes and secretion assay Hepatocytes were isolated [25], diluted $\left(10^{6}\right.$ cells $\left./ \mathrm{ml}\right)$ in EMEM and incubated with glucagon at $37^{\circ} \mathrm{C}$ in a shaking water bath.

Isolation of rat adipocytes and pre-adipocytes Adipocytes were isolated according to the method of Rodbell [26] with some modifications, as described [27]. Adipocytes $\left(10^{6}\right.$ cells $\left./ \mathrm{ml}\right)$ were incubated in Krebs-Ringer-bicarbonate-HEPES (KRBH) ( $5 \mathrm{mmol} / \mathrm{l}$ glucose, $3 \% \mathrm{wt} / \mathrm{vol}$. BSA) with test agents at $37^{\circ} \mathrm{C}$ in a shaking water bath. Primary rat pre-adipocytes were isolated from epididymal fat pads. Cells were differentiated into mature adipocytes, as described [28].

Lipolysis and FGF-21 assay Lipolysis was determined by measuring the concentration of released glycerol in incubation medium using 'free glycerol reagent' [27]. The results were normalised to cell number and are expressed in $\mathrm{mmol} / 10^{6}$ cells. Immunoneutralisation of released FGF-21 was performed in rat pre-adipocytes differentiated in vitro for 6 days using $1 \mu \mathrm{g}$ anti-FGF-21 polyclonal antibody or a non-specific control $\operatorname{IgG}$ antibody. In rat pre-adipocytes differentiated in vitro for 6 days, the lipolysis experiment was started $28 \mathrm{~h}$ after treatment with $F g f-21$ small interfering (si)RNA or control (scrambled) siRNAs (Santa Cruz Biotechnology, Santa Cruz, CA, USA). Rat FGF-21 concentration was detected by mouse/rat FGF-21 ELISA (detection range: 40-2,560 pg/ml) (Biovendor, Brno, Czech Republic) 
and murine FGF-21 concentration was detected by mouse recombinant FGF21 RIA (detection range: $0.234-30 \mathrm{ng} / \mathrm{ml}$ ) (Phoenix Pharmaceuticals, Burlingame, CA, USA).

Secretion assay using isolated primary adipocytes Isolated primary adipocytes were incubated in DMEM solution containing test agents for various time periods at $37^{\circ} \mathrm{C}$.

Differentiation of 3T3-L1 fibroblasts into adipocytes, and secretion assays 3T3-L1 fibroblasts (American Type Culture Collection, LGC Standards, Wesel, Germany) were differentiated to mature adipocytes [27, 28]. Criteria for differentiation were: $\geq 1,000$-fold increase of Fabp 4 relative to Gapdh and lipid droplet formation in $\geq 95 \%$ cells (data not shown). All experiments were performed between the eighth and tenth day after induction of the differentiation. Adipocytes were pre-incubated overnight in serum-free DMEM, washed with PBS and incubated with test agents. Medium was collected and clarified by centrifugation $(800 \mathrm{~g}, 10 \mathrm{~min})$ and stored at $-80^{\circ} \mathrm{C}$.

Western blot Proteins were isolated from 3T3-L1 adipocytes, as described and resolved on SDS-PAGE [27]. Membranes were incubated with anti-FGF21 antibody (ESM Table 2), washed and exposed to a secondary antibody (ESM Table 2). Signals were detected by enhanced chemiluminescence (GE Healthcare Europe, Freiburg, Germany) and visualised using $\mathrm{x}$-ray film. Membranes were stripped and incubated with anti$\beta$-actin antibody, as the loading control [27].

\section{Real-time PCR}

Intron-spanning primers for murine $F g f-21$ were designed by ProbeFinder 2.45 (Roche Applied Science; ESM Table 3). RTPCR was performed as described [27]. The specificity of the PCR products was monitored on the basis of melting-curves analysis. The relative quantification of the target gene product was calculated using LightCycler Software 4.5 with the reaction's efficiency correction.

\section{Statistical analyses}

Statistical analyses were performed using SPSS 19 (SPSS, Chicago, IL, USA). All data are expressed as means \pm SEM, unless otherwise stated. Baseline characteristics were compared as previously described [20]. Serial changes in glucose, insulin, glucagon and FGF-21 after glucagon or placebo administration were analysed using ANOVA for repeated measures. When the ANOVA was significant, changes were compared with baseline values using the Student's $t$ test for paired analysis for normally distributed data. In the case of skewed data, the non-parametric Wilcoxon test was used. All significances were two-sided and $p$ values $<0.01$ were regarded as statistically significant (as corrected by Bonferroni for multiple testing). The baseline value was calculated as the mean of the -30 and 0 min values. AUCs, calculated by the trapezoid method, were used to compare the timecourses of each variable after glucagon and placebo administration, as described previously [2].

Data from animal and cell culture studies were derived from at least three independent experiments, performed in triplicate, unless otherwise stated. Differences between groups were analysed for significance using one-way ANOVA and Tukey's post hoc analysis. Statistical significance was assumed when $p<0.05$.

\section{Results}

Glucagon stimulates lipolysis

Human study The baseline characteristics of the study participants are presented in Table 1. Plasma glucagon concentrations increased by eight- to ninefold $30 \mathrm{~min}$ after glucagon administration ( $355.9 \pm 21.7 \mathrm{ng} / \mathrm{l}[\mathrm{LP}] ; 340.6 \pm 25.6 \mathrm{ng} / 1$ [type 1 diabetes]) and returned to baseline levels after $240 \mathrm{~min}$ in both groups (ESM Fig. 1a, b). The overall rise of glucagon was in agreement with maximal or submaximal physiological fluctuations during the course of the day or during hypoglycaemia [29]. The glucagon $\mathrm{AUC}_{240}$ values increased in both study groups $\left(921.4 \pm 96.4 \mathrm{ngl}^{-1} \mathrm{~min}\right.$ [type 1 diabetes] and $800 \pm$ 71.9 [LP]; $p<0.01$ ] and were comparable $(p=0.4)$. In type 1 diabetic people, glucose levels increased maximally after $60 \mathrm{~min}$ with a slight decrease towards baseline after $240 \mathrm{~min}$ (5.3 $\pm 0.4 \mathrm{mmol} / 1$ [baseline], $11 \pm 0.5$ [60 $\mathrm{min}$ ] and $7.8 \pm 0.6$ [240 min]; $p<0.01$ ) (ESM Fig. 1c). Glucose levels slightly increased after $30 \mathrm{~min}$ in LP and returned to baseline levels after $120 \mathrm{~min}(4.5 \pm 0.2 \mathrm{mmol} / \mathrm{l}$ [baseline], $6.2 \pm 0.4$ [30 $\mathrm{min}$ ] and $3.7 \pm 0.2$ [120 $\mathrm{min}] ;(p<0.01)]$ (ESM Fig. 1d). The glucoseAUC 240 increased in patients with type 1 diabetes $(p<0.01)$ but not in LP $(p=0.917)$, and values were higher in type 1 diabetic individuals compared with LP $\left(453.6 \pm 36.8 \mathrm{mmoll}^{-1}\right.$ min [type 1 diabetes] vs $240.7 \pm 7.5$ [LP]; $p<0.05$ ). Plasma insulin concentrations did not change after glucagon or placebo administration in patients with type 1 diabetes $(p=0.2-0.6)$ (ESM Fig. 1e). Compared with the glucose excursions, plasma insulin levels showed a similar increase with a peak after $30 \mathrm{~min}$ followed by a decrease towards the baseline level after 120 min only in LP $(32.9 \pm 4.1 \mathrm{pmol} / 1$ [baseline], $199.3 \pm 21.7$ [30 $\mathrm{min}]$ and $26.7 \pm 6.9$ [120 min]; $p<0.01$ ) (ESM Fig. 1f).

In LP plasma, the increase in insulin levels over the first 120 min after glucagon administration caused a significant decrease in NEFA concentration (a surrogate marker of lipolysis) (NEFAAUC ${ }_{0-120}: 35.3 \pm 3.2 \mathrm{mmoll}^{-1} \mathrm{~min}$ (glucagon) vs $137.3 \pm 10.8$ (placebo); $p<0.01$ ) (ESM Fig. 2). In contrast, NEFA levels showed a comparable increase over the first 
120 min following glucagon or placebo administration in patients with type 1 diabetes (ESM Fig. 2). Compared with placebo, glucagon induced a sustained increase in circulating plasma NEFA concentrations over the last $120 \mathrm{~min}$ of the test period in both LP $\left(\right.$ NEFAAUC $_{120-240}: 592.1 \pm 58.7$ mmoll $^{-1}$ min [glucagon] vs $126.1 \pm 6.1$ [placebo]; $p<0.01$ ) and in type 1 diabetic study participants (NEFAAUC ${ }_{120-240}: 243.9 \pm$ $20.7 \mathrm{mmoll}^{-1} \min$ [glucagon] vs $126 \pm 5.4$ [placebo]; $p<0.01$ ) (Fig. 1a). a

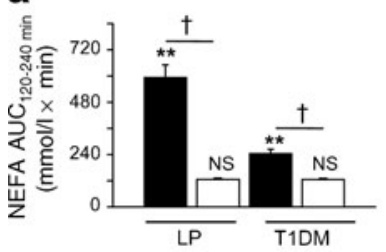

C

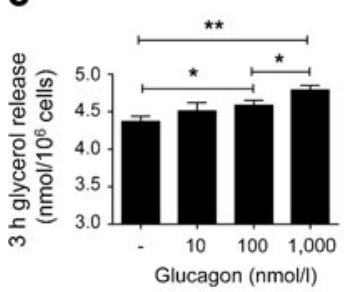

e

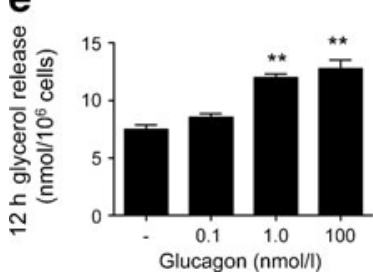

b

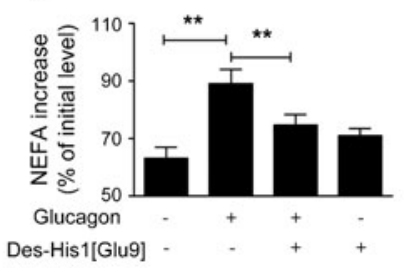

d

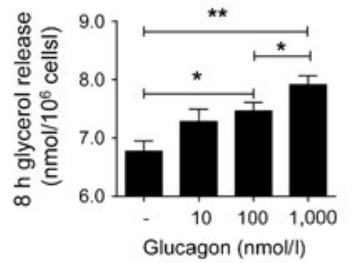

f

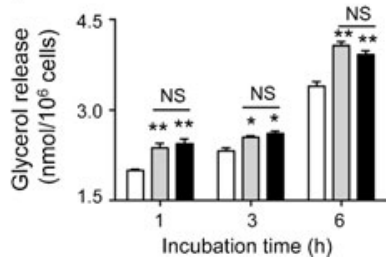

Fig. 1 (a) Mean $\left( \pm\right.$ SEM) variations in $\mathrm{AUC}_{120-240}$ min of NEFA concentration after glucagon (black bars) or placebo (white bars) administration in patients with type 1 diabetes (T1DM) and lean participants (LP); ${ }^{* *} p<0.01$ vs baseline; ${ }^{\dagger} p<0.01$, glucagon vs placebo; NS, non-significant. Lipolysis is presented during the last $120 \mathrm{~min}$ after glucagon administration in both LP and patients with type 1 diabetes. (b) Determination of in vivo lipolysis in mice with STZ-induced insulinopenic diabetes injected with vehicle, glucagon $(0.05 \mathrm{mg} / \mathrm{kg}$ body weight) with or without the peptidal glucagon antagonist desHis1[Glu9] glucagon amide ( $2 \mathrm{mg} / \mathrm{kg}$ body weight) ( $n=6$ per group). Changes in plasma NEFA (surrogate markers of lipolysis) $4 \mathrm{~h}$ after injection with test substances are expressed as \% increase vs initial NEFA concentration (prior to injection of test agents) in the corresponding treatment group. Dose-dependent glucagon-stimulated lipolysis in isolated primary rat adipocytes after $3 \mathrm{~h} \mathrm{(c)} \mathrm{or} 8 \mathrm{~h}(\mathbf{d})$. Effects of a prolonged incubation $(12 \mathrm{~h})$ of in vitro differentiated primary adipocytes derived from healthy rats with glucagon at different doses (e). Time- and dose-dependent stimulation of lipolysis by glucagon in adipocytes isolated from rats with STZ-induced insulinopenic diabetes (f); white bars, vehicle; grey bars, $1 \mathrm{nmol} / 1$ glucagon; black bars, $100 \mathrm{nmol} / 1$ glucagon. The experiments were repeated at least four times. Figures show means \pm SEM. ${ }^{*} p<0.05$ and ${ }^{* *} p<0.01$ vs basal or vs highlighted treatment groups. des-His1[Glu9], des-His1[Glu9] glucagon amide; NS, not significant
Animal in vivo study A counter-regulatory increase of insulin prevents glucagon from stimulating lipolysis under physiological conditions, and therefore glucagon-induced lipolysis was studied in mice with insulinopenic diabetes (Table 2). Plasma NEFA levels increased $4 \mathrm{~h}$ after glucagon administration in diabetic mice compared with vehicleinjected mice, and this was blocked effectively by the glucagon antagonist des-His1[Glu9] glucagon amide (Fig. 1b).

In vitro lipolysis Glucagon stimulated release of glycerol (a surrogate marker of lipolysis) from adipocytes isolated from non-diabetic rats after 2 and $8 \mathrm{~h}$ (Fig. 1c). The maximum increase in lipolysis $(\sim 19 \%$ increase vs control, $p<0.01)$ was observed after $8 \mathrm{~h}$ (Fig. 1d). Because of the limited survival of isolated mature adipocytes, the prolonged effects of glucagon on lipolysis were studied using isolated rat preadipocytes that underwent experimental differentiation to mature adipocytes. Glucagon stimulated lipolysis after a $12 \mathrm{~h}$ incubation period during in vitro pre-adipocyte differentiation (Fig. 1e). Furthermore, glucagon time-dependently stimulated lipolysis from adipocytes isolated from rats 4 days after the induction of insulinopenic diabetes (Fig. 1f). The maximum stimulation of lipolysis $(\sim 25 \%$ above basal) was observed after $1 \mathrm{~h}$ of incubation with $1 \mathrm{nmol} / \mathrm{l}$ glucagon.

\section{Glucagon increases circulating FGF-21}

Human study Administration of glucagon led to a sustained increase in plasma FGF-21 concentration over a total test period of $240 \mathrm{~min}$ in both study groups (Fig. 2a, b). The increase in FGF-21 was detectable after 30,60, 120, 180 and $240 \mathrm{~min}$ in LP $(0.14 \pm 0.01 \mathrm{ng} / \mathrm{ml}$ [baseline] vs $0.23 \pm$ 0.02 [30 min], $0.29 \pm 0.02$ [60 $\mathrm{min}$ ], $0.27 \pm 0.02$ [120 $\mathrm{min}$ ], $0.27 \pm 0.02[180 \mathrm{~min}]$ and $0.26 \pm 0.01$ [240 $\mathrm{min}] ; p<0.01)$ (Fig. 2a) and in the type 1 diabetes group $(0.33 \pm 0.05 \mathrm{ng} / \mathrm{ml}$ [baseline] vs $0.45 \pm 0.04$ [30 $\mathrm{min}$ ], $0.47 \pm 0.05$ [60 $\mathrm{min}$ ], $0.48 \pm 0.05$ [120 $\mathrm{min}$ ], $0.48 \pm 0.05[180 \mathrm{~min}]$ and $0.47 \pm 0.05$ [240 min]; $p<0.01$ ) (Fig. 2b). Plasma FGF-21 concentrations decreased after placebo administration in both study groups $(p<0.01)$.

The FGF-21AUC 240 was higher after glucagon administration than after placebo in LP $\left(290.8 \pm 65.6 \mathrm{ng} \mathrm{ml}^{-1} \mathrm{~min}\right.$ [glucagon] vs $-61.6 \pm 4.8$ [placebo]; $p<0.001$ ) (Fig. $2 \mathrm{c}$ ) and in the type 1 diabetes group $\left(134.4 \pm 35.7 \mathrm{ngml}^{-1} \min\right.$ [glucagon] vs $-56.6 \pm 6.1$ [placebo], $p<0.001$ ) (Fig. 2d).

Animal study Glucagon increased plasma FGF-21 concentrations in lean mice fasted for 24 or $4 \mathrm{~h}$ (Fig. 2e and f, respectively). The increase in FGF-21 plasma concentration in animals fasted for $24 \mathrm{~h}$ was evident after $120 \mathrm{~min}$ and sustained at $240 \mathrm{~min}$ (Fig. 2e). In animals fasted for $4 \mathrm{~h}$, FGF-21 plasma concentrations were increased at $15 \mathrm{~min}$ 
after glucagon injection, with the maximum increase after $120 \mathrm{~min}$, and declined slightly after $240 \mathrm{~min}$ (Fig. 2f).

Glucagon increased FGF-21 plasma concentrations in diabetic mice fasted for $24 \mathrm{~h}$ by approximately 1.8 -fold after
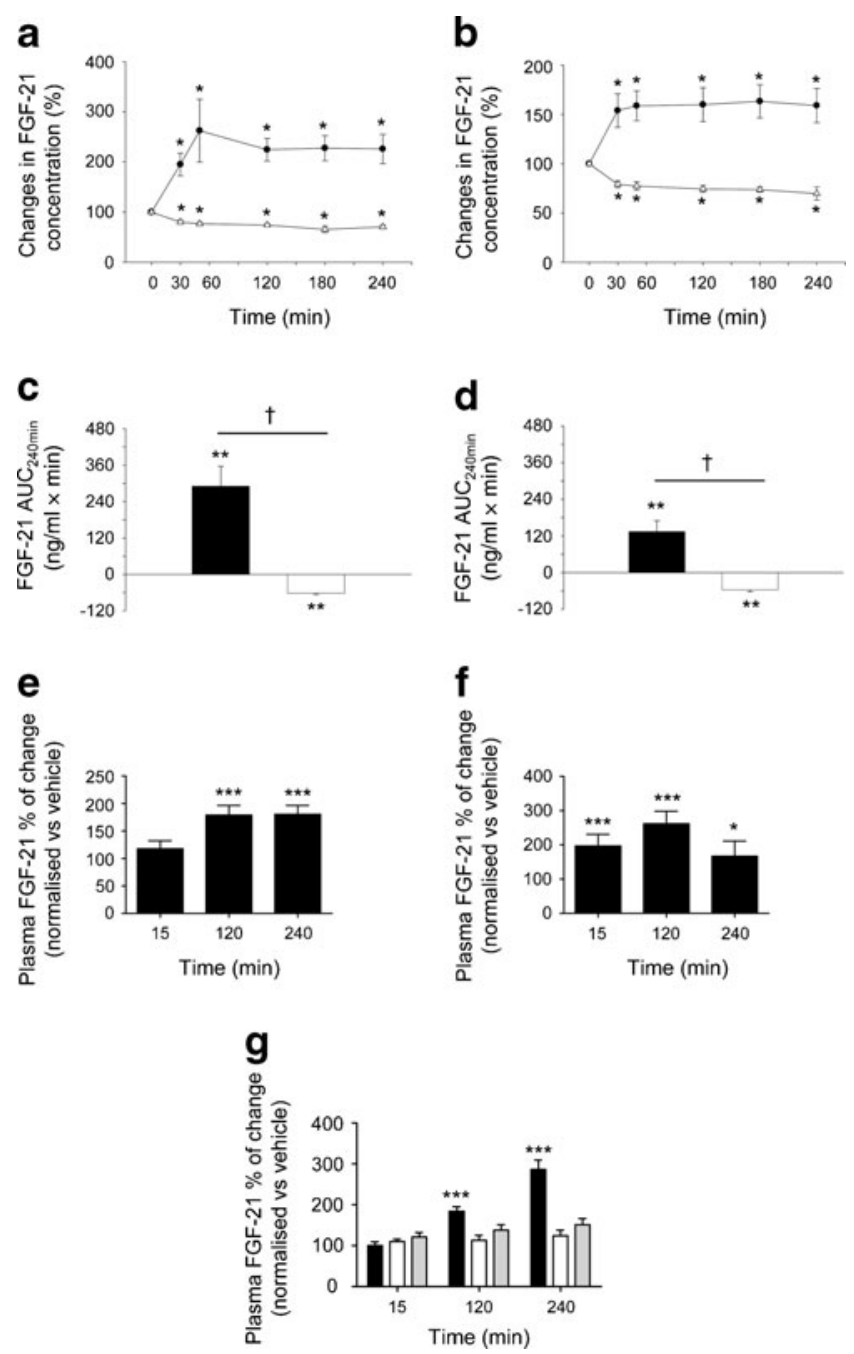

Fig. 2 (a, b) Mean $( \pm$ SEM) changes in FGF-21 after the administration of glucagon (black symbols) or placebo (white symbols) in: (a) 13 lean participants; and (b) 13 patients with type 1 diabetes $\left({ }^{*} p<0.01\right)$. The 0 min value was calculated as the mean of two baseline values ( -30 and $0 \mathrm{~min}$ ). All values are presented relative to the baseline. (c, d) Mean $( \pm \mathrm{SEM})$ variations in incremental $\mathrm{AUC}_{240}\left(\mathrm{IAUC}_{240}\right)$ of FGF-21 after glucagon (black bars) or placebo administration (white bars) in: (c) 13 lean participants; and (d) 13 patients with type 1 diabetes. ${ }^{* *} p<0.01$ vs baseline; ${ }^{\dagger} p<0.001$ vs placebo. (e, f) Time-dependent changes in FGF21 plasma concentration in lean non-diabetic adult male mice fasted for $24 \mathrm{~h}(\mathbf{e})$ or $4 \mathrm{~h}(\mathbf{f})$ and subsequently injected i.p. with glucagon $(0.05 \mathrm{mg} / \mathrm{kg}$ body weight) or vehicle. (g) Time-dependent changes in plasma FGF-21 concentrations in mice with insulinopenic diabetes, injected with glucagon (black bars), peptidal glucagon antagonist des-His1[Glu9] glucagon amide ( $2 \mathrm{mg} / \mathrm{kg}$ body weight) (white bars) or glucagon together with desHis1[Glu9] glucagon amide (grey bars). All animals were killed $4 \mathrm{~h}$ after injection of test substances. The experiments were performed in $n=6$ animals per treatment group. The results have been normalised relative to changes in corresponding animal groups treated with vehicle only. ${ }^{*} p<0.05$ and ${ }^{* * *} p<0.01$ vs vehicle-treated controls unless otherwise stated
$120 \min (p<0.05$ vs vehicle) and by approximately 2.9 -fold after $240 \mathrm{~min}$ ( $p<0.001$ vs vehicle) (Fig. 2g). Des-His1[Glu9] glucagon amide effectively blocked the glucagon-stimulated increase in plasma FGF-21 (Fig. 2g).

Glucagon stimulates hepatic Fgf-21 expression in vivo Liver $F g f-21$ mRNA expression increased by approximately 35 and 39\% in non-diabetic mice fasted for 4 and $24 \mathrm{~h}$ after glucagon injection, respectively (Fig. 3a). An approximately $45 \%$ increase in hepatic Fgf-21 mRNA expression was detectable in glucagon-treated mice with insulinopenic diabetes, and was blocked by des-His1[Glu9] glucagon amide (Fig. 3b). Fgf-21 mRNA expression levels in the fat tissue of glucagon-treated non-diabetic healthy mice (Fig. 3c) or mice with insulinopenic diabetes (Fig. 3d) were comparable with those detected in vehicle-treated animals.

Glucagon stimulates FGF-21 release from isolated rat hepatocytes and adipocytes

Glucagon increased FGF-21 secretion from isolated primary hepatocytes by approximately $20 \%$ (Fig. 4 a, b). In adipocytes isolated from rats fasted for $18 \mathrm{~h}$, glucagon stimulated Fgf-21mRNA expression by approximately 53\% (Fig. 4c), whereas there was only an approximately $7 \%$ increase in adipocytes derived from non-fasted rats $(p<0.05)$ (Fig. $4 d$ ).

In 3T3-L1 adipocytes glucagon dose-dependently stimulated FGF-21 secretion after $8 \mathrm{~h}$, although to a lower extent than nTZD (10 nmol/l) (Fig. 4e). In addition, glucagon (100 nmol/l) stimulated FGF-21 protein synthesis and Fgf-21 mRNA expression after $48 \mathrm{~h}$, although less potently than nTZD (Fig. 4f, g).

Role of FGF-21 in regulation of lipolysis in adipocytes isolated from animals with insulinopenic diabetes

We investigated the in vitro impact of FGF-21 on lipolysis using isolated rat adipocytes derived from STZ-diabetic rats. FGF-21 at $100 \mathrm{nmol} / \mathrm{l}$ stimulated glycerol release from adipocytes isolated from healthy rats after 2 and $4 \mathrm{~h}$ (Fig. 5a-c). In adipocytes isolated from diabetic animals, an increase in glycerol release was observed at $1 \mathrm{nmol} / 1$ FGF-21 (Fig. 5d-f), indicating that adipocytes isolated from STZ-treated rats are more susceptible to the lipolytic action of FGF-21. Overall, the lipolytic activity of FGF-21 was less potent than that of glucagon, isoprenaline or adrenaline (epinephrine) (Fig. 5g). To elucidate the contribution of FGF-21 to glucagon-stimulated lipolysis, adipocytes were incubated with glucagon $(1$ or $100 \mathrm{nmol} / \mathrm{l})$ in the presence or absence of anti-FGF-21 antibody or an $\operatorname{IgG}$ antibody (negative control) (Fig. 5h). Immunoneutralisation of FGF-21 prevented FGF-21 from stimulating 

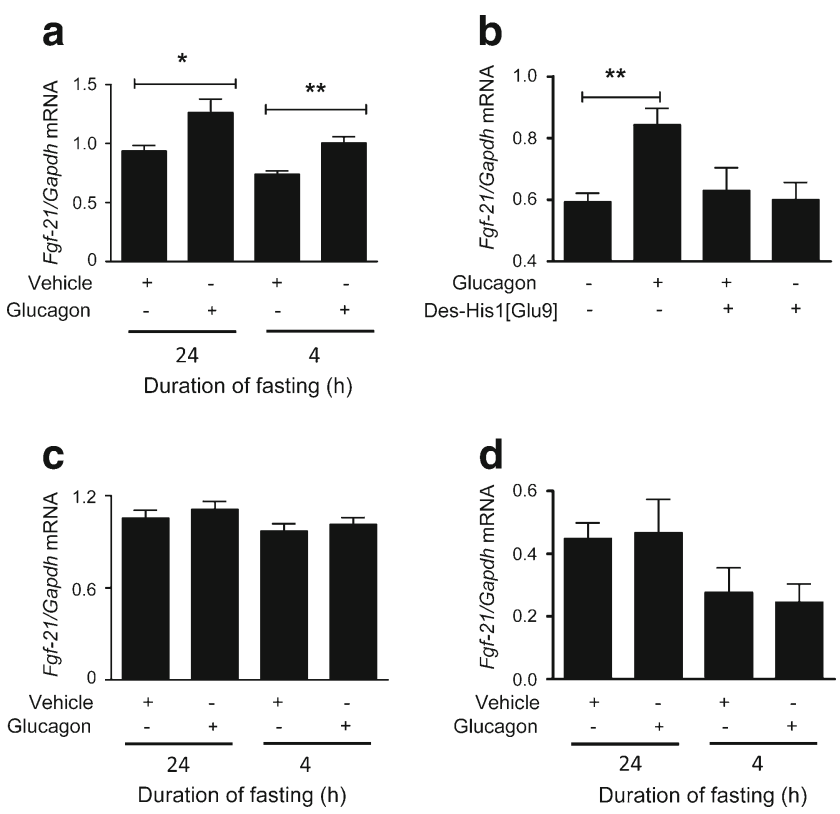

Fig. 3 (a) Changes in Fgf-21 mRNA expression in livers of 24 h- or 4 h-fasted adult non-obese healthy mice injected with either glucagon or vehicle. Animals fasted for the indicated time periods were injected once with either vehicle or glucagon $(0.05 \mathrm{mg} / \mathrm{kg}$ body weight). After $4 \mathrm{~h}$ animals were killed and the hepatic expression of Fgf-21 was determined ( $n=6$ animals per group). (b) Expression of $F g f-21$ mRNA in livers of $4 \mathrm{~h}$-fasted adult mice with STZ-induced insulinopenic diabetes. Mice were injected once i.p. with either vehicle or glucagon $(0.05 \mathrm{mg} / \mathrm{kg}$ body weight), or glucagon together with the peptidal glucagon antagonist des-His1[Glu9] glucagon amide $(2 \mathrm{mg} / \mathrm{kg}$ body weight). Changes in Fgf-21 mRNA expression in fat tissue in nondiabetic healthy mice (c) or mice with insulinopenic diabetes (d) fasted for 24 or $4 \mathrm{~h}$. The expression level of $F g f-21$ mRNA in livers or white adipose tissue (epididymal fat) obtained from $n=6$ animals was normalised vs Gapdh. ${ }^{*} p<0.05$ and $^{* *} p<0.01$ vs vehicle-treated animals

lipolysis and attenuated $100 \mathrm{nmol} / \mathrm{l}$ glucagon-stimulated lipolysis compared with controls. In agreement with these results, $F g f-21$ mRNA reduction by approximately $66 \%$ in rat pre-adipocytes differentiated into mature adipocytes markedly attenuated glucagon-stimulated lipolysis, compared with cells treated with non-targeting siRNA (Fig. 5i, j), suggesting that glucagon regulates lipolysis, at least, in part via FGF-21.

\section{Discussion}

Recently, it has been shown that glucagon modulates Fgf-21 expression [12-15]. Here, we extend these observations by reporting for the first time that glucagon increases, independently of endogenous insulin levels, circulating levels of FGF-21 in humans and rodents. Moreover, glucagon stimulates lipolysis in vitro, in healthy and type 1 diabetic humans and in insulinopenic rodents. Glucagon stimulates hepatic FGF-21 production regardless of circulating insulin levels. In isolated adipocytes glucagon stimulates FGF-21 secretion and lipolysis, while immunoneutralisation of FGF21 or reduction of $F g f-21$ expression attenuates lipolytic activity of glucagon.
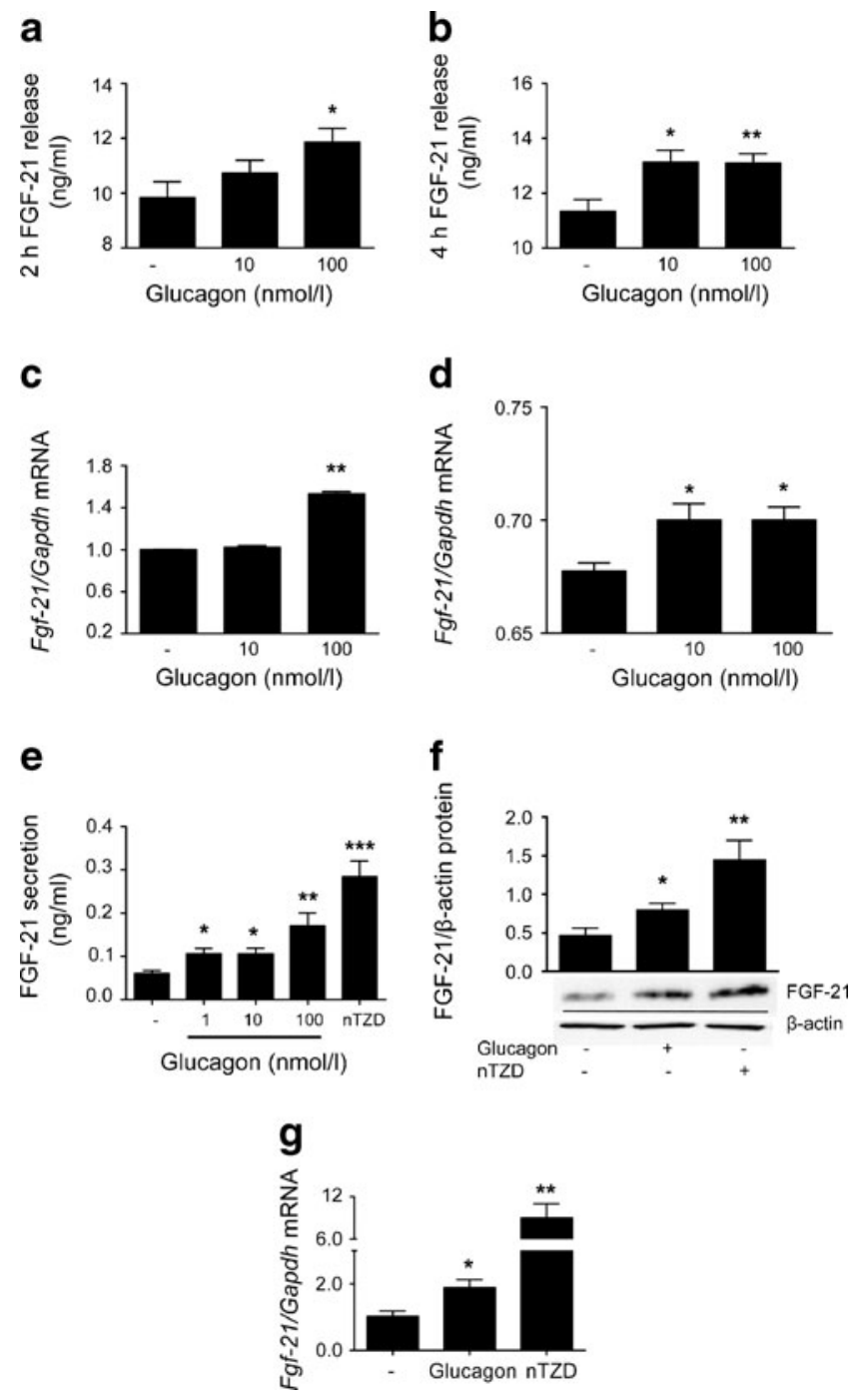

Fig. 4 Time- and dose-dependent stimulation of FGF-21 secretion by glucagon from isolated primary rat hepatocytes. (a, b) Hepatocytes were exposed to glucagon at the doses indicated for $120 \mathrm{~min}$ (a) or $240 \mathrm{~min}$ (b), or were treated with vehicle (indicated as minus) and released FGF-21 in the incubation medium was measured. (c, d) Stimulation of $F g f-21$ mRNA expression by glucagon in primary adipocytes isolated from $18 \mathrm{~h}$-fasted (c) or non-fasted (d) lean rats. Adipocytes were incubated with glucagon and the expression of $F g f-21$ mRNA (normalised against Gapdh) was evaluated using real-time PCR. The experiment was repeated three times and the results are expressed as mean \pm SEM. (e) FGF-21 secretion from 3T3-L1 adipocytes exposed for $8 \mathrm{~h}$ to either glucagon $(1-100 \mathrm{nmol} / \mathrm{l})$ or nTZD (10 nmol/l). (f, g) FGF-21 protein levels (f) and Fgf-21 mRNA expression (g) in 3T3-L1 adipocytes exposed for $48 \mathrm{~h}$ to either glucagon $(100 \mathrm{nmol} / \mathrm{l})$ or nTZD $(10 \mathrm{nmol} / \mathrm{l})$. The levels of FGF-21 protein and Fgf-21 RNA expression were normalised vs Gapdh, or $\beta$-actin, respectively. ${ }^{*} p<0.05,{ }^{* *} p<0.01$ and ${ }^{* * *} p<0.001$ vs vehicle-treated groups (indicated as -). Each experiment was repeated three times 

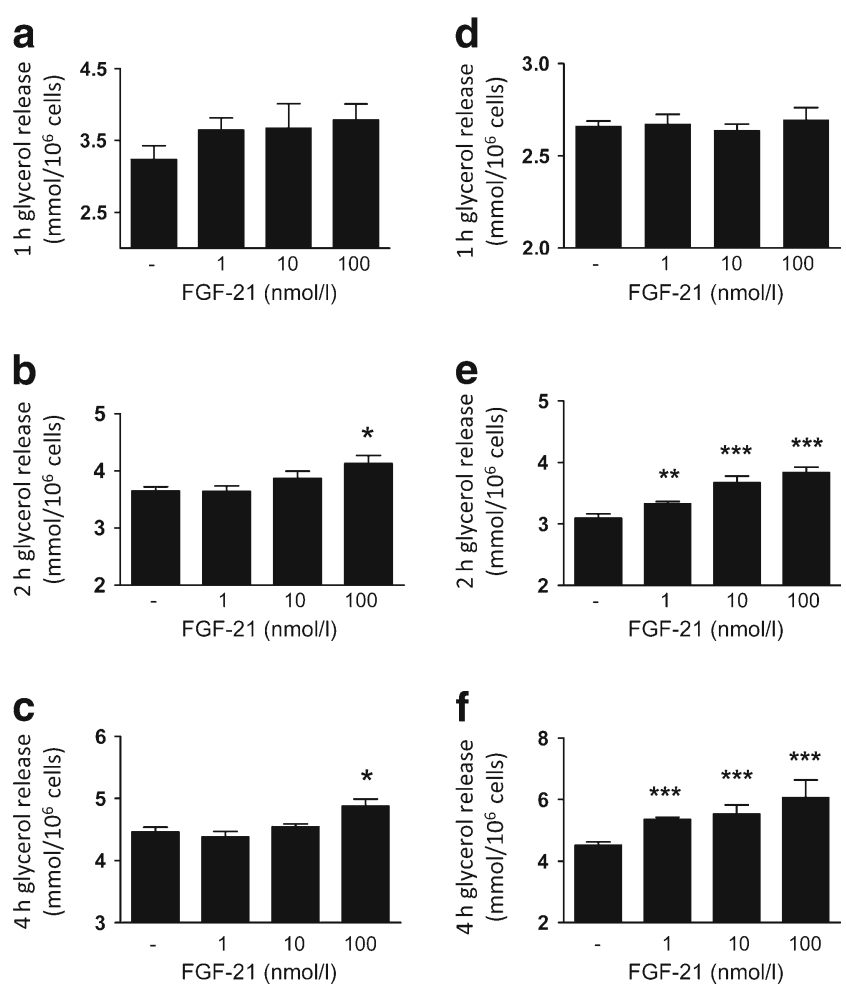

Fig. 5 (a-f) Stimulation of lipolysis by FGF-21 in isolated primary adipocytes derived from non-diabetic $(\mathbf{a}-\mathbf{c})$ and STZ-diabetic rats $(\mathbf{d}-\mathbf{f})$ after $1 \mathrm{~h}(\mathbf{a}, \mathbf{d}), 2 \mathrm{~h}(\mathbf{b}, \mathbf{e})$ and $4 \mathrm{~h}(\mathbf{c}, \mathbf{f})$. (g) Comparison of lipolytic activities of FGF-21 (10 nmol/l), glucagon (Glcg; $10 \mathrm{nmol} / \mathrm{l})$, adrenaline (Adr; $10 \mathrm{nmol} / \mathrm{l})$ and isoprenaline (Isopr; $1,000 \mathrm{nmol} / \mathrm{l})$ in isolated rat adipocytes exposed to test agents for $6 \mathrm{~h}$. (h) Consequences of immunoneutralisation of FGF-21 on glucagon-stimulated lipolysis from isolated adipocytes. Cells treated with either a non-specific control IgG antibody (white bars) or anti-FGF-21 antibody (black bars) were exposed for $6 \mathrm{~h}$ to either $10 \mathrm{nmol} / \mathrm{l} \mathrm{FGF}-21$ (positive control), or glucagon $(1 \mathrm{nmol} / \mathrm{l}$ or $100 \mathrm{nmol} / \mathrm{l})$. Attenuation of glucagon-stimulated lipolysis (glucagon at $10 \mathrm{nmol} / \mathrm{l}$ ) after $6 \mathrm{~h}$ (i) or $12 \mathrm{~h} \mathrm{(j)} \mathrm{in} \mathrm{rat} \mathrm{pre-}$ adipocytes differentiated for 6 days into mature adipocytes and after suppression of $F g f-21$ mRNA expression by $66 \%$ using $F g f-21$ siRNA (black bars). Control experiments were performed using cells treated with non-targeting siRNA (white bars). Each experiment was repeated three times. ${ }^{*} p<0.05,{ }^{* *} p<0.01$ and ${ }^{* * *} p<0.001$ vs vehicle or between the indicated groups. ${ }^{\dagger} p<0.05$ comparison of cells exposed to FGF-21 or glucagon and treated with anti-FGF-21 antibody to cells exposed to vehicle and treated with anti-FGF-21 antibody (h). ${ }^{\star} p<0.05$ comparison of cells pre-treated with $F g f-21$ siRNA and exposed to glucagon to cells pre-treated with $F g f-21$ siRNA and exposed to vehicle

The increase of FGF-21 plasma concentration by exogenous glucagon regardless of endogenous insulin production is somehow intriguing, in view of the contradictory results of earlier studies showing that insulin regulates FGF-21 [12, 15, 17, 30]. Exogenous insulin increased plasma FGF-21 and $F g f-21$ mRNA expression in skeletal muscle in humans [30]. FGF-21 was detectable in four of 14 patients before and 11 of 14 patients after insulin administration. In healthy humans an approximately sevenfold increase in plasma insulin led to an approximately $10 \%$ increase in circulating FGF-21 [17]. In contrast, removal of exogenous insulin in
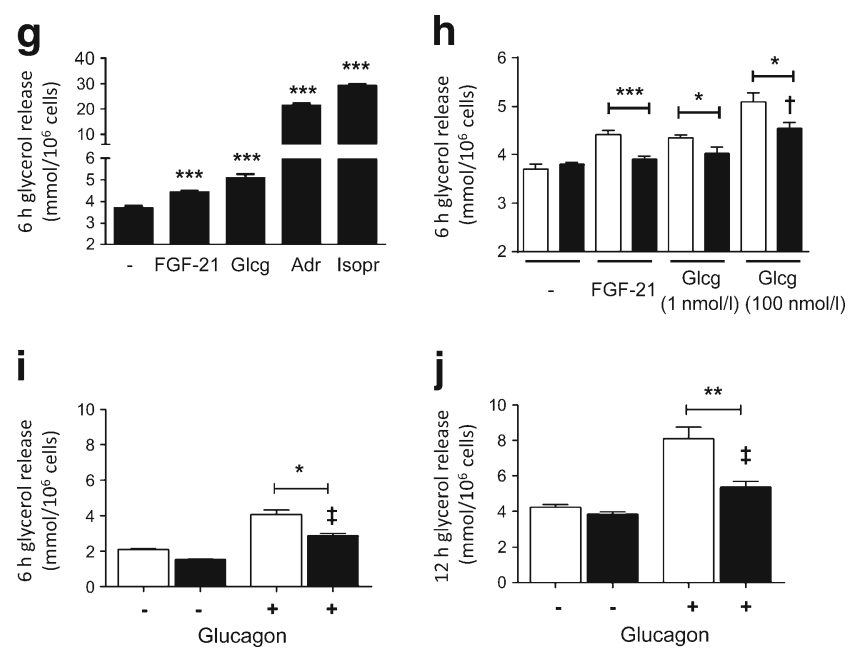

Fig. 5 (continued)

humans with type 1 diabetes resulted in an approximately $10 \%$ increase in plasma FGF-21 [18], suggesting that insulin reduces FGF-21. In addition, insulin inhibited glucagonstimulated $F g f-21$ expression in rat hepatocytes [12].

In our study, high glucagon levels were associated with an increase in FGF-21 in both humans and rodents regardless of endogenous insulin concentration. In contrast to the experimental settings of the above-cited human studies, we did not investigate the influence of exogenous insulin on FGF-21.

Glucagon increased hepatic Fgf-21 expression in both healthy and insulinopenic rodents, and stimulated FGF-21 secretion from isolated hepatocytes regardless of the duration of the fasting period, suggesting that the rise in circulating FGF-21 results from increased hepatic production. Glucagon stimulated FGF-21 secretion, expression and protein production in vitro in rodent adipocytes; however, no increase in Fgf-21 mRNA expression was detectable in white adipose tissue in glucagon-treated animals. Highest density of glucagon receptors are found in hepatocytes [31, $32]$, but much less abundant in adipocytes [31, 33]. We therefore hypothesise that glucagon primarily stimulates FGF-21 secretion in the liver leading to high circulating FGF-21 which, in turn, may concomitantly suppress endogenous FGF-21 production in adipocytes. However, the contribution of FGF-21 to glucagon-stimulated lipolysis was clear from the in vitro experiments performed on differentiated adipocytes with suppressed $F g f-21$ expression or with immunoneutralised FGF-21. Both experiments clearly showed that FGF-21 participates in glucagon-stimulated lipolysis.

Our results are compatible with the observations that FGF-21 stimulates lipolysis in murine 3T3-L1 adipocytes [3]. FGF-21 stimulated lipolysis in isolated rodent adipocytes, although with lower potency than glucagon, adrenaline or isoprenaline. Lipolysis was more potently stimulated 
in adipocytes isolated from insulinopenic animals; this could be explained by a higher FGF-21 sensitivity, as the circulating FGF-21 levels were lower in insulinopenic animals than in controls. However, the receptor status in adipocytes has not been investigated.

The results of our current study, however, need to be interpreted cautiously, because of several limitations. Although our in vitro experiments with rodent cells clearly show a causative relationship between FGF-21 and glucagonstimulated lipolysis, we were not able to show in vivo that glucagon-induced lipolysis in the fasting state in both healthy and type 1 diabetic or insulinopenic animals/humans is causally related to FGF-21 level. In addition, we did not evaluate the effects of glucagon administration on Fgf-21 expression in the fed state. Furthermore, our experiments were performed on adipocytes and hepatocytes isolated from rodents, as human tissues were not accessible. In isolated human adipocytes, long-term incubation of FGF-21 inhibited even adrenalinestimulated lipolysis [6], suggesting that these discrepancies may reflect the use of different species.

In line with possible species differences, we found that FGF-21 levels in type 1 diabetic patients were higher than in controls, while in animals the opposite was found. Other possible reasons for the differences are that type 1 diabetic patients were older and more obese than healthy volunteers. It is known that FGF-21 levels are higher in obese patients [34]. Furthermore, FGF-21 plasma concentrations are not solely determined by glucagon, but are also affected by other hormones such as growth hormone $(\mathrm{GH})$, which is able to induce hepatic FGF-21 production [35]. In humans with type 1 diabetes mellitus GH levels are higher than in healthy lean individuals [36]. Finally, in contrast to humans with type 1 diabetes, who injected a long-acting insulin analogue on the evening before the test, the study mice did not receive any insulin treatment and lost approximately $60 \%$ of fat pad mass after STZ injection.

Another limitation of the human part of the study is the relatively high dose of exogenous glucagon used. However, the maximal fold rise in glucagon levels was kept within the maximal physiological daily fluctuations [30]. Because of this limitation, we can state only that glucagon can increase the release of FGF-21 or lipolysis at the concentrations used in our study. Investigation of the ability of glucagon to induce these effects at lower concentrations, such as under fasting conditions or after a protein-rich meal, needs further dose-titration controlled clamp studies.

In summary, we show that glucagon increases circulating FGF-21 independently of endogenous insulin levels. In contrast to the rapid onset of the lipolytic actions of glucagon, the FGF-21-induced stimulation of lipolysis is delayed. Taking the results together, glucagon seems to first stimulate lipolysis directly, with prolonged lipolytic actions presumably mediated in part by FGF-21.
Acknowledgements We thank A. Adamidou from Charité-University Medicine Berlin, Berlin, Germany, for her contribution to the collection of human data. We thank M. Petrovitsch from University Hospital Munich (Munich, Germany), K. Sprengel from the German Institute of Human Nutrition Potsdam-Rehbruecke (Nuthetal, Germany), and A. Schönknecht and P. Exner from Charité-University Medicine Berlin (Berlin, Germany) for excellent technical assistance.

Funding Support was from: Deutsche Forschungsgemeinschaft (STR558) to M. Z. Strowski; German Diabetes Foundation to M. Z. Strowski and A. M. Arafat; and graduate school (GK1208) of the Deutsche Forschungsgemeinschaft to A. M. Arafat. M. Skrzypski is the recipient of a 2012 Annual Fellowship for Young Scientists from the Foundation for Polish Science (FNP).

Duality of interest The authors confirm that there is no duality of interest associated with this manuscript.

Contribution statement AMA, MZS, PKa and MSk designed the study, obtained the data and wrote the manuscript. AFHP, BW and KWN contributed to the study design, reviewed/edited the manuscript and contributed to the discussion. EP-O, PKo, MSa, DS and TW obtained the data, drafted the article and revised the manuscript. All authors have given final approval to the current version to be published.

\section{References}

1. Kharitonenkov A, Shiyanova TL, Koester A et al (2005) FGF-21 as a novel metabolic regulator. J Clin Invest 115:1627-1635

2. Nishimura T, Nakatake Y, Konishi M, Itoh N (2000) Identification of a novel FGF, FGF-21, preferentially expressed in the liver. Biochim Biophys Acta 1492:203-206

3. Inagaki T, Dutchak P, Zhao G et al (2007) Endocrine regulation of the fasting response by PPAR alpha-mediated induction of fibroblast growth factor 21. Cell Metab 5:415-425

4. Potthoff MJ, Inagaki T, Satapati S et al (2009) FGF21 induces PGC-1alpha and regulates carbohydrate and fatty acid metabolism during the adaptive starvation response. Proc Natl Acad Sci U S A 106:10853-10858

5. Hotta Y, Nakamura H, Konishi M et al (2009) Fibroblast growth factor 21 regulates lipolysis in white adipose tissue but is not required for ketogenesis and triglyceride clearance in liver. Endocrinology 150:4625-4633

6. Arner P, Pettersson A, Mitchell PJ, Dunbar JD, Kharitonenkov A, Ryden M (2008) FGF21 attenuates lipolysis in human adipocytes - a possible link to improved insulin sensitivity. FEBS Lett 582:1725-1730

7. Zhang X, Yeung DC, Karpisek M et al (2008) Serum FGF21 levels are increased in obesity and are independently associated with the metabolic syndrome in humans. Diabetes 57:1246-1253

8. Berglund ED, Li CY, Bina HA et al (2009) Fibroblast growth factor 21 controls glycemia via regulation of hepatic glucose flux and insulin sensitivity. Endocrinology 150:4084-4093

9. Lefebvre PJ, Luyckx AS (1969) Effect of insulin on glucagon enhanced lipolysis in vitro. Diabetologia 5:195-197

10. Perea A, Clemente F, Martinell J, Villanueva-Penacarrillo ML, Valverde I (1995) Physiological effect of glucagon in human isolated adipocytes. Horm Metab Res 27:372-375

11. Harmon JS, Sheridan MA (1992) Effects of nutritional state, insulin, and glucagon on lipid mobilization in rainbow trout, Oncorhynchus mykiss. Gen Comp Endocrinol 87:214-221 
12. Uebanso T, Taketani Y, Fukaya M et al (2009) Hypocaloric highprotein diet improves fatty liver and hypertriglyceridemia in sucrose-fed obese rats via two pathways. Am J Physiol Endocrinol Metab 297:E76-E84

13. Uebanso T, Taketani Y, Yamamoto $H$ et al (2011) Paradoxical regulation of human FGF21 by both fasting and feeding signals: is FGF21 a nutritional adaptation factor? PLoS One 6:e22976

14. Badman MK, Pissios P, Kennedy AR, Koukos G, Flier JS, Maratos-Flier E (2007) Hepatic fibroblast growth factor 21 is regulated by PPARalpha and is a key mediator of hepatic lipid metabolism in ketotic states. Cell Metab 5:426-437

15. Berglund ED, Kang L, Lee-Young RS et al (2010) Glucagon and lipid interactions in the regulation of hepatic AMPK signaling and expression of PPARalpha and FGF21 transcripts in vivo. Am J Physiol Endocrinol Metab 299:E607-E614

16. Longuet C, Sinclair EM, Maida A et al (2008) The glucagon receptor is required for the adaptive metabolic response to fasting. Cell Metab 8:359-371

17. Mai K, Andres J, Biedasek K et al (2009) Free fatty acids link metabolism and regulation of the insulin-sensitizing fibroblast growth factor-21. Diabetes 58:1532-1538

18. Mai K, Bobbert T, Groth C et al (2010) Physiological modulation of circulating FGF21: relevance of free fatty acids and insulin. Am J Physiol Endocrinol Metab 299:E126-E130

19. Arafat MA, Otto B, Rochlitz H et al (2005) Glucagon inhibits ghrelin secretion in humans. Eur J Endocrinol 153:397-402

20. Arafat AM, Perschel FH, Otto B et al (2006) Glucagon suppression of ghrelin secretion is exerted at hypothalamus-pituitary level. J Clin Endocrinol Metab 91:3528-3533

21. Jesmin S, Zaedi S, Maeda S, Yamaguchi I, Goto K, Miyauchi T (2006) Effects of a selective endothelin a receptor antagonist on the expressions of iNOS and eNOS in the heart of early streptozotocininduced diabetic rats. Exp Biol Med (Maywood) 231:925-931

22. Kim NN, Stankovic M, Cushman TT, Goldstein I, Munarriz R, Traish AM (2006) Streptozotocin-induced diabetes in the rat is associated with changes in vaginal hemodynamics, morphology and biochemical markers. BMC Physiol 6:4

23. Wu KK, Huan Y (2008) Streptozotocin-induced diabetic models in mice and rats. Curr Protoc Pharmacol (Suppl 40):5.47.1-5.47.14

24. Berger J, Tanen M, Elbrecht A et al (2001) Peroxisome proliferatoractivated receptor-gamma ligands inhibit adipocyte 11 beta hydroxysteroid dehydrogenase type 1 expression and activity. J Biol Chem 276:12629-12635
25. Seglen PO (1976) Preparation of isolated rat liver cells. Methods Cell Biol 13:29-83

26. Rodbell M (1964) Metabolism of isolated fat cells. I. effects of hormones on glucose metabolism and lipolysis. J Biol Chem 239:375-380

27. Skrzypski M, Le T, Kaczmarek P et al (2011) Orexin A stimulates glucose uptake, lipid accumulation and adiponectin secretion from 3T3-L1 adipocytes and isolated primary rat adipocytes. Diabetologia 54:1841-1852

28. Nugent C, Prins JB, Whitehead JP et al (2001) Potentiation of glucose uptake in 3T3-L1 adipocytes by PPAR gamma agonists is maintained in cells expressing a PPAR gamma dominantnegative mutant: evidence for selectivity in the downstream responses to PPAR gamma activation. Mol Endocrinol 15: $1729-1738$

29. Cherrington AD (1997) Chapter 10: the metabolic actions of glucagon. In: Draznin B, Rizza B (eds) Clinical research in diabetes and obesity, vol. 1. Methods, assessment and metabolic regulation. Part II: effects of hormones on substrate metabolism. Humana Press, Totowa, pp 221-242

30. Hojman P, Pedersen M, Nielsen AR et al (2009) Fibroblast growth factor-21 is induced in human skeletal muscles by hyperinsulinemia. Diabetes 58:2797-2801

31. Iwanij V, Vincent AC (1990) Characterization of the glucagon receptor and its functional domains using monoclonal antibodies. J Biol Chem 265:21302-21308

32. Watanabe M, Hayasaki H, Tamayama T, Shimada M (1998) Histologic distribution of insulin and glucagon receptors. Braz J Med Biol Res 31:243-256

33. Svoboda M, Tastenoy M, Vertongen P, Robberecht P (1994) Relative quantitative analysis of glucagon receptor mRNA in rat tissues. Mol Cell Endocrinol 105:131-137

34. Reinehr T, Woelfle J, Wunsch R, Roth CL (2012) Fibroblast growth factor 21 (FGF-21) and its relation to obesity, metabolic syndrome, and nonalcoholic fatty liver in children: a longitudinal analysis. J Clin Endocrinol Metab 97:2143-2150

35. Chen W, Hoo RL, Konishi M et al (2011) Growth hormone induces hepatic production of fibroblast growth factor 21 through a mechanism dependent on lipolysis in adipocytes. J Biol Chem 286:34559-34566

36. Herlihy OM, Perros P (2000) Elevated serum growth hormone in a patient with type 1 diabetes: a diagnostic dilemma. Diabetes Metab Res Rev 16:211-216 